\title{
CORRESPONDENCE
}

\section{Cerebrospinal fluid tests for neurosyphilis diagnosis}

\author{
Francesco Drago, ${ }^{1,2}$ Giulia Ciccarese (1) , ${ }^{1}$ Aurora Parodi ${ }^{1,2}$
}

'Dermatologic Clinic, Ospedale Policlinico San Martino Istituto di Ricovero e Cura a Carattere Scientifico per l'Oncologia, Genova, Liguria, Italy ${ }^{2}$ Section of Dermatology, Department of Health Sciences (DISSAL), University of Genoa, Genoa, Italy

\section{Correspondence to} Dr Giulia Ciccarese, Dermatologic Clinic, Ospedale Policlinico San Martino Istituto di Ricovero e Cura a Carattere Scientifico per l'Oncologia, Genova 16132, Italy; giuliaciccarese@libero.it Published Online First 4 May 2020

\section{SLinked}

- http://dx.doi.org/10.1136/ sextrans-2020-054512

- http://dx.doi.org/10.1136/ sextrans-2019-054198

\section{Check for updates}

(C) Author(s) (or their employer(s)) 2020. No commercial re-use. See rights and permissions. Published by BMJ.

To cite: Drago F, Ciccarese G Parodi A. Sex Transm Infect 2020;96:387.
Dear Editor,

We agree with Shiva $e t$ al ${ }^{1}$ about the relevance of assessing Treponema pallidum particle agglutination (TPPA) titres in the cerebrospinal fluid (CSF) samples of patients with suspected neurosyphilis. For many years, we have been using $T$. pallidum haemagglutination test (TPHA) both in diagnosing neurosyphilis and in the follow-up of our patients after treatment. It would have been interesting to know the trend of CSF-TPPA titres over time in Shiva's patients. We consider as serological cure in syphilis a fourfold decline in the initial TPHA titres within 12 months after therapy and a titre $\geq 1: 640$ in CSF as specific for neurosyphilis diagnosis. At 12 months, $92 \%$ of our patients were serologically cured. The rate of concordance with venereal disease research laboratory (VDRL) is about 90\% and the use of TPHA is crucial in patients in whom non-treponemal tests are negative. CSF treponemal tests can be useful in identifying asymptomatic neurosyphilis where VDRL sensitivity is only $10 \%$. In our experience, TPHA-CSF dilution cut-off of $\geq 1: 640$ has a high diagnostic specificity in diagnosing neurosyphilis. The concordance with VDRL-CSF positivity is $100 \%$. There is no clear consensus on the diagnosis of neurosyphilis and it continues to be a problem relying on various combinations of reactive CSF tests results, alterations of cell count or proteins in the CSF or clinical manifestations. ${ }^{2}$ Further studies with a well established criteria for neurosyphilis are needed to better validate the utility of these and other markers. Among them is the evaluation of CXCL-13 levels, ${ }^{3}$ a B-cell-attracting chemokine, which increases in patients with neurosyphilis and declines after therapy. Remarkably, this chemokine increases also in asymptomatic neurosyphilis and can be used to confirm or deny a neurosyphilis in patients with CSF pleocytosis, as happens in patients with HIV infection or in patients with nonreactive CSF-VDRL $\left(50 \%-70 \%\right.$ of neurosyphilis). ${ }^{3}$

\section{Handling editor Anna Maria Geretti}

Contributors The authors equally contributed to the work.

Funding The authors have not declared a specific grant for this research from any funding agency in the public, commercial or not-for-profit sectors.

Competing interests None declared.

Patient consent for publication Not required.

Provenance and peer review Not commissioned; internally peer reviewed.

ORCID iD

Giulia Ciccarese http://orcid.org/0000-0001-8363-0195

\section{REFERENCES}

1 Shiva F, Goldmeier D, Lane P, et al. Cerebrospinal fluid TPPA titres in the diagnosis of neurosyphilis. Sex Transm Infect 2020;96:388-9.

2 Drago F, Merlo G, Ciccarese G, et al. Changes in neurosyphilis presentation: a survey on 286 patients. J Eur Acad Dermatol Venereol 2016;30:1886-900.

3 Marra CM, Tantalo LC, Sahi SK, et al. C XCL13 as a cerebrospinal fluid marker for neurosyphilis in HIV-infected patients with syphilis. Sex Transm Dis 2010;37:283-7. 